\title{
Treatment with acetazolamide of brain-stem and spinal paroxysmal disturbances in multiple sclerosis
}

\author{
V. Voiculescu, BEATRICE PRUSKAUER-A postol, AND C. AleCU
}

From the Neurological Clinic, G. Marinescu Hospital, Bucharest, Romania

SYNOPSIS Nine cases of multiple sclerosis with paroxysmal disorders were treated with acetazolamide. In most cases a brain-stem origin of the seizures was suggested by their particular pattern: crossed syndromes (facial spasm associated with contralateral weakness of the arm and leg, paroxysmal paraesthesiae in one side of the face and weakness of the contralateral leg), paroxysmal dysarthria, and ataxia. One patient with a Brown-Séquard syndrome complained of paroxysmal paraesthesiae in the lower limbs, for which a spinal origin was admitted. In all patients the paroxysmal disorders were promptly suppressed or markedly reduced by acetazolamide.

Recurrent attacks of dysarthria accompanied by transient motor and sensory disturbances in patients with multiple sclerosis have been described by Franklin and Brickner (1947), Anderman et al. (1959), Espir et al. (1966), Kuroiwa and Shibasaki (1967), Harrison and McGill (1969). The present report is concerned with our experience in nine additional cases successfully treated with acetazolamide. The observations of five patients will be briefly presented.

\section{CASE 1}

A housewife, aged 53 years, had complained for the last seven years of weakness of the legs. In 1967 she had an episode of diplopia for a few weeks. In August 1968 she experienced dizziness; sometimes she was incontinent of urine. She was admitted to hospital in October 1968. On examination the gait was ataxic. All tendon reflexes were brisk. The abdominal reflexes could not be elicited. The plantar responses were extensor. The left arm showed an intention tremor. Nystagmus was present on lateral gaze. Ophthalmoscopic examination revealed pallor of both optic discs. On walking she experienced brief attacks of stiffness in the left side of the body, and found it impossible to maintain her balance. During the attacks her speech became difficult.

Acetazolamide, $250 \mathrm{mg}$ three times daily was successful in stopping the attacks. Suppression of the drug was followed by reappearance of the attacks, which ceased immediately with resumption of the medication.

(Accepted 16 August 1974.)

\section{CASE 2}

A 52 year old man was admitted on 13 December 1968. Three months before he had noticed unsteadiness of gait and dysarthria. On examination his gait was wide-based and ataxic. He had a bilateral intention tremor. The plantar responses were equivocal. In January 1969 he began having brief attacks during which he could not articulate. At the same time he had a spasm in the right half of the face and weakness in the left arm and leg. If walking, he would fall. The attacks were precipitated by emotional stress, by physical exertion, and by overbreathing. A short attack was elicited after three minutes of overbreathing in a mixture of $\mathrm{O}_{2}$ and $7 \% \mathrm{CO}_{2}$. Phenytoin and phenobarbitone were tried without effect. The attacks were stopped within three days after the initiation of treatment with acetazolamide $250 \mathrm{mg}$ thrice daily. Withdrawal of the drug was always followed by the reappearance of the attacks, which were quickly stopped by resuming medication. The same effect was obtained with carbamazepine (Tegretol). The patient was last seen in September 1969. He was free of all symptoms. He took no medication.

\section{CASE 3}

A 24 year old woman was admitted to hospital in July 1969. She had experienced a first episode of diplopia and clumsiness of the left arm and leg in 1963. The symptoms lasted a few weeks and subsided after a course of corticotrophin (ACTH). She was quite well until October 1968 when she began to drag the left foot and complained of frequency of 191 
of a burning sensation in the left side of the face and neck associated with a weakness of the right leg. The attacks recurred 20 to 25 times a day. Her gait was spastic and ataxic. The tendon reflexes were pathologically brisk with bilateral extensor plantar responses. The abdominal reflexes were absent. Muscle tone was slightly increased in the legs and in them vibration sensibility was grossly impaired. A moderate intention tremor was present. The examination revealed pallor of both optic discs. Acetazolamide, $250 \mathrm{mg}$ three times daily, stopped the attacks. When acetazolamide was suspended, the attacks recurred to disappear again after resumption of the drug.

\section{CASE 4}

A 68 year old man complained of attacks during which he experienced a burning pain in the right cheek associated with paroxysmal incoordination of the left hand and a slight stiffness in both legs. The attacks recurred 20 to 30 times a day. The patient had a diagnosis of retrobulbar neuritis 20 years before. On examination a bilateral sign of Babinski and a pallor of both optic discs were found. After $750 \mathrm{mg}$ acetazolamide daily, the number of attacks fell to one to three in 24 hours.

\section{CASE 5}

A man aged 46 years was well until two years before, when he developed attacks of severe pain and paraesthesiae in the left leg lasting about one minute and recurring two to three times in the day. The attacks were provoked mainly by effort such as climbing into a bus. A sudden noise - the ringing of the telephone in the morning while the patient was lying in bedalso induced the attack. The painful attack appeared regularly during ejaculation. Walking was difficult because of stiffness of the right leg. The knee and ankle jerks were brisk. The abdominal reflexes were absent and the right plantar response was extensor. Over the left side of the body there was thermanaesthesia and hypalgesia up to the seventh thoracic dermatome.

The attacks disappeared after administration of acetazolamide to reappear when the drug was withdrawn. Carbamazepine was also highly efficient against the paroxysms. The patient was seen two years later when he suffered a new exacerbation with paraesthesiae in the neck and face.

\section{DISCUSSION}

Paroxysmal dysarthria, ataxia, diplopia, and tonic spasms of the limbs are the commonest neurological disturbances occurring during the transient attacks of multiple sclerosis. This type of seizure illustrated also by our first three cases suggests a brain-stem origin. The arguments for this assumption are: (1) the crossed character of some symptoms (spasm in the right half of the face associated with weakness in the left arm and leg in case 2 , burning sensation in the left side of the face and neck accompanied by weakness of the right leg in case 3 and in another two cases not reported in detail); (2) the frequency of paroxysmal dysarthria or other symptoms indicating the participation of the cranial nerves; (3) the tonic character of the motor seizures; (4) the absence of critical or intercritical changes in the electroencephalogram.

Experimental work by Kreindler et al. (1958) showed that both in cats and rats a convulsive seizure was regularly induced when special points in the brain-stem were stimulated. The bulbopontine seizure definitely differs from a cortical seizure in that it has a very marked tonic component. Very characteristic tonic seizures were observed by Kreindler et al. (1962) in a patient with encephalomyelitis in whom pathological examination showed a plaque of de- $\stackrel{\mathbb{Q}}{\Omega}$ myelination in the medulla involving the pyra- 0 중 midal decussation.

In case 5 , in which painful seizures appeared in a patient with a Brown-Séquard syndrome, a spinal origin of the paroxysmal attacks seems? very probable. The convulsive capacity of the spinal cord has been studied by Kreindler et al. (1951) in experiments on cats with transected cord in which tonic seizures of the hind limbs were obtained after intravenous injection of amidopyrine.

It is difficult to explain the mechanism of paroxysmal discharges starting in the brain-stem or in the spinal cord respectively. In the cases with paroxysmal crossed symptoms suggesting a pontine localization, one is inclined to accept an involvement of the demyelinating long tracts by the paroxysmal discharge. The verification of this assumption requires further studies. The theory of vascular spasm postulated by Franklin and Brickner (1947) seems improbable in view of the fact that we could elicit an attack during overbreathing of a mixture of $\mathrm{O}_{2}$ and $\mathrm{CO}_{2}$ (case 2).

It is known that, among the anticonvulsant drugs, carbamazepine has a relatively specific 
activity against the paroxysmal disturbances occurring in patients with multiple sclerosis. Our results with acetazolamide proved almost as good as those obtained with carbamazepine.

\section{REFERENCES}

Andermann, F., Cosgrove, J. B. R., Lloyd-Smith, D., and Walters, A. M. (1959). Paroxysmal dysarthria and ataxia in multiple sclerosis. A report of 2 unusual cases. Neurology (Minneap.), 9, 211-215.

Espir, M. L. E., Watkins, S. M., and Smith, H. V. (1966). Paroxysmal dysarthria and other transient neurological disturbances in disseminated sclerosis. Journal of Neurology, Neurosurgery, and Psychiatry, 29, 323-330.

Franklin, C. R., and Brickner, R. M. (1947). Vasospasm associated with multiple sclerosis. Archives of Neurology and Psychiatry (Chic.), 58, 125-162.
Harrison, M., and McGill, J. I. (1969). Transient neurological disturbances in disseminated sclerosis: a case report. Journal of Neurology, Neurosurgery, and Psychiatry, 32, 230-232.

Kreindler, A., Cardas, M., Petrescu, A., and Botez, M. I. (1962). Considérations sur l'étiopathogénie des crises toniques dans l'encéphalomyélite disséminée, Revue Neurologique, 107, 353-369.

Kreindler, A., Voiculescu, V., Ungher, I., and Voinescu, I. (1951). Acţiunea convulsivantă a piramidonului la pisică şi câine. Buletin Stiintific. Academia Republicii Populare Române. Sectiunea de Ştiinte Medicale, 3, 419-423.

Kreindler, A., Zuckermann, E., Steriade, M., and Chimion, D. (1958). Electroclinical features of convulsions induced by stimulation of brain stem. Journal of Neurophysiology, 21, 430-436.

Kuroiwa, Y., and Shibasaki, H. (1967). Carbamazepine for tonic seizure in multiple sclerosis. Lancet, 1, 116. 